\title{
Development of Abrasive Grain Coating Technology Protective Polymer Casing for Water-Abrasive Cutting
}

\author{
Olga G. Kozhus ${ }^{1, \mathrm{a}^{*}}$, Gennady V. Barsukov ${ }^{1, \mathrm{~b}}$, Larisa Yu. Frolenkova ${ }^{1, \mathrm{c},}$ \\ Evgeny R. Arkhipov ${ }^{1, d}$ and Alexander A. Kazarin ${ }^{1, e}$ \\ ${ }^{1}$ Orel State University named after I.S. Turgenev, Komsomolskaya st. 95, Orel, Russian \\ Federation \\ aokozhus@mail.ru, bawj@list.ru, clarafrolenkova@yandex.ru, darhipov199806@yandex.ru, \\ ekazarin1999@gmail.com
}

Keywords: Abrasive, Polymer, Waterjet Cutting, Fluidized Bed, Film Coating

\begin{abstract}
The article presents the technology of covering abrasive grains with a protective polymer shell, which allows to reduce the wear of the focusing tube of the nozzle of a hydroabrasive installation. A description of the manufacturing process of a prototype abrasive with a polymer coating in a fluidized bed is presented in order to determine the critical processing modes at which a high-quality product will be obtained in a minimum operating time of the installation.
\end{abstract}

\section{Introduction}

The productivity of applying a polymer shell to the surface of an abrasive grain is estimated as the mass of the processed material per hour of operation of the installation. At the same time, important processes must be ensured that take place during the encapsulation of the abrasive in a fluidized bed. The speed of their passage affects the processing performance. These processes include the adhesion of the polymer to the abrasive surface followed by drying. In this case, it is necessary to exclude the agglomeration of particles and their deposition on the gratings, meshes and walls of the equipment.

The performance of fluidized bed encapsulation of abrasives is achieved through selection of equipment, polymer type, spray parameters and abrasive properties.

The choice of polymer affects the flow rate of the spray solution during the coating process on the abrasive. The amount of polymer sprayed determines the processing efficiency and the performance of the encapsulation process. However, it is necessary to control the volume of consumption of the polymer solution and the increment in the mass of the processed abrasive. An increase in processing productivity requires an increase in the consumption of the sprayed polymer and the acceleration of the processes occurring in the coating zone. The processing modes should ensure the rapid passage of the processes of polymer spraying, its deposition and adhesion on the abrasive surface, followed by drying. Such modes will be critical and will provide the highest possible processing performance [3].

\section{Main part}

The process of encapsulation of a polymer shell on an abrasive under critical technological conditions depends on the following characteristics:

1. Construction and size of the coating booth:

- air flow;

- the temperature of the supplied air.

2. Characteristics of the polymer solution:

- type of polymer and composition of the coating solution; 
- consumption of polymer solution;

- the initial temperature of the polymer solution;

- humidity.

3. Parameters of polymer solution spraying:

- characteristics of the spray nozzle (spray angle, nozzle flow rate, orifice diameter);

- the position of the sprayer (above or below the abrasive layer);

- distance from the nozzle edge to the abrasive layer;

- the concentration of the polymer solution;

- spray pressure.

4. Parameters of abrasive particles:

- the size of the abrasive;

- the mass of the processed material in the installation chamber;

- roughness of the abrasive surface;

- wettability of the abrasive surface.

The intensification of the coating process on the abrasive surface is limited by the capabilities of the equipment used. The parameters of the fluidized bed are determined by the volume of the loaded abrasive and the dimensions of the treatment chamber. The speed and productivity of processing in this case is defined as the ratio of the consumption of abrasive to the surface area in the processing zone[4,5,6].

This is due to the fact that when passing air through the loaded abrasive, it is necessary to ensure the flow rate $\omega$, when the particles become fluidized and begin to move. Further increasing the air

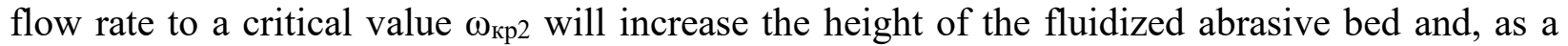
result, the distance between the particles. Subsequent increase in speed above the critical value $\omega_{\text {кр2 }}$ will lead to the carryover of the abrasive from the processing area (Figure 1).

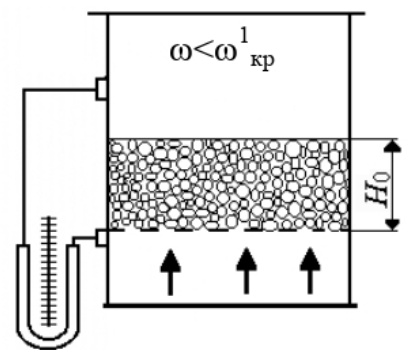

a)

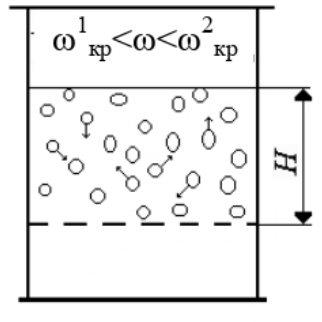

b)

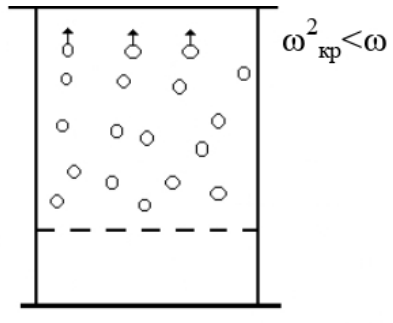

c)

Fig. 1. Influence of the air flow rate on the process liquefaction of abrasive a) - abrasive layer without movement; b) -fluidized abrasive layer; c) - removal of abrasive from the processing area

Thus, an increase in the productivity of applying a polymer coating to an abrasive due to a larger loaded volume of abrasive leads to an increase in the size of the installation and the need to use more powerful air injection equipment. Therefore, the critical processing conditions will be determined by the choice of the type and characteristics of the corresponding equipment.

The parameters and characteristics of the equipment will determine the required air flow rate and air flow rate to ensure and maintain a stable fluidized bed.

Another way to increase the productivity of processing on the existing equipment can be an increase in the speed of application of the coating and its subsequent rapid drying. This can be achieved through the use of a fast-drying polymer and an increase in mortar consumption. 
However, an increase in the volume of the applied polymer per unit time will lead to an increase in the mass of the abrasive particle to a critical value, when it cannot be and be maintained in suspension. This will lead to agglomeration of particles and their deposition on the lattice and walls of the installation and to stop the encapsulation process.

Unvaporated droplets of sprayed coating solution are more likely than in the central flow area to form agglomerates with a liquid, uncured coating.

The appearance of liquid drops in the near-wall zone may be due to the fact that the flow rate of the sprayed polymer solution is increased $[1,2]$.

In the upper part of the layer, where liquid drops of a polymer coating solution appear, as well as along the walls of the chamber, where these drops can be carried by turbulent air pulsations, both independently and together with abrasive particles, agglomerates of abrasive grains with an unhardened coating may appear. Their large weight, as well as vertical pulsations of the speed of air and abrasive particles, contribute to the fall of agglomerates to the bottom.

The reason for the ingress of wet abrasive particles to the bottom of the chamber and the formation of agglomerates caused by this process can be the slow evaporation of the solvent water, not only due to the lowered temperature in some areas of the chamber, but also due to the excess of not evaporated polymer solution.

To intensify the process of applying a polymer coating to an abrasive, it is necessary to improve the conditions for blowing the polymer solution through the fluidized bed, to reduce the likelihood of adhesion of abrasive agglomerates on the walls of the chamber, to reduce the vortex movement of particles from the bottom of the chamber to the fluidized layer and back. This is largely due to the difference in the movement of the abrasive flow in the center of the chamber and on its walls, where the operating temperature decreases due to heat losses and the speed of the moving flow decreases.

It is possible to ensure the uniformity of drying temperature and flow rate from the center of the chamber to the boundaries of the liquefied bed by constructive modernization of the liquefaction chamber. A decrease in porosity is equivalent to an increase in the frequency of collision of abrasive particles with a wall at low kinetic energy. You can get rid of this by reducing the wall resistance to air flow. This can be achieved by blowing additional air into it through the walls.

To do this, we will install a mesh cylinder in the liquefaction chamber. The abrasive is loaded not into the installation chamber, but inside the cylinder (Figure 2).

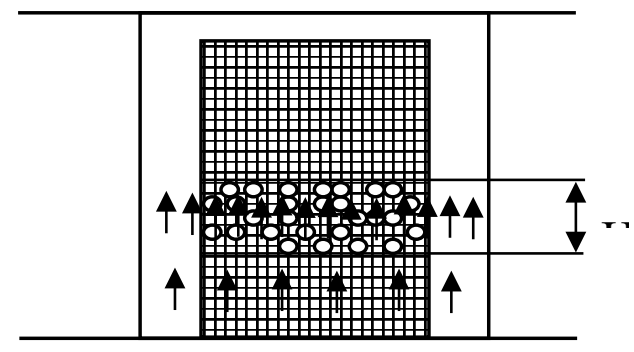

Fig. 2. The design of the chamber for creating a liquefied abrasive layer with a mesh cylinder for operation in critical modes of polymer coating

There are no abrasive adhesion conditions on the walls of the mesh cylinder of the chamber. There is no stable boundary layer near the mesh wall, in which the air flow speed is equal to the operating 
speed. The likelihood of the deposition of agglomerates or wet abrasive particles on the gas distribution grid is reduced due to the uneven distribution of the working speed of the gas flow over the section of the working chamber, the uneven distribution of the air temperature over this section, the near-wall feature of reducing the flow rate in the chamber for applying a protective coating to abrasive particles.

Consequently, the introduced design changes make it possible to increase the absolute velocity of the fluidizing agent near the walls of the mesh cylindrical chamber and equalize its value with other parts of the value. This means that the concentration of abrasive particles near the walls will be commensurate with other zones of the processing chamber. Increasing the relative particle velocity significantly reduces the likelihood of agglomeration.

In the course of the study, it was found that the agglomeration of adhering pairs of particles will proceed faster where the probability of their collision is more likely, that is, where their concentration is greater. Maintaining a liquid state, the viscosity of a polymer liquid significantly depends on the local temperature of the process, the length and shape of macromolecules. Further, the influence of each of the reasons is considered separately $[7,8]$.

The homogeneity of the coating was studied (table 1). At the first stage, the abrasive surface was examined at low magnification (Figure 3). If, during the study, defects in the uniformity of the coating were found, the surface area of interest is considered at the highest possible resolution.
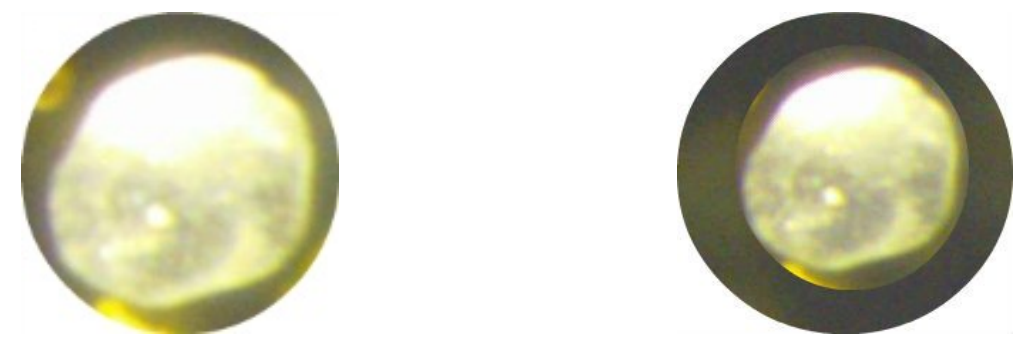

Fig. 3. Photos of a prototype abrasive inpolymer shell (LeicoMZ 16 microscope, $\times 150$ magnification)

Table 1. Assessment of coating uniformity

\begin{tabular}{|c|l|c|c|}
\hline $\begin{array}{c}\text { № } \\
\mathrm{p} / \mathrm{p}\end{array}$ & \multicolumn{1}{|c|}{ Coating uniformity index } & Result & $\kappa_{n}$ \\
\hline 1 & Holes & Not detected & 1 \\
\hline 2 & Integrity & Not broken & 1 \\
\hline 3 & Chips, delamination & Not detected & 1 \\
\hline 4 & Dust splashes & Not detected & 1 \\
\hline 5 & Coverage uniformity & Yes & 1 \\
\hline
\end{tabular}

The value of the uniformity of the coating for each selected grain is determined by the formula:

$O_{a}=\frac{\sum \kappa_{n}}{n} * 100 \%$, 
where $\kappa_{n}$ - indicator score;

$n$ - the number of indicators of uniformity of the coating, is defined.

Based on the results of the assessment, it was concluded that the uniformity of the coating of the abrasive in the polymer shell is $100 \%$.

Next, the thickness of the polymer coating on the abrasive was determined by determining the difference between the linear size of the outer surface of the abrasive with polymer coatings and the size before applying the shell (after dissolving the polymer shell in water) (Figure 4).

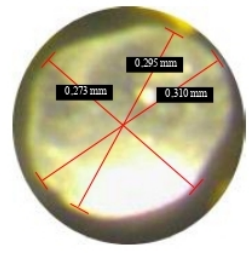

a)

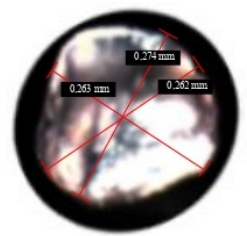

b)

Fig. 4. Measurement of abrasive grain with polymer coating a-abrasive in a polymer sheath, $b$ - abrasive without a polymer sheath

Measurements at selected points on the grain surface were recorded in the test report (Table 2). Then the thickness of the polymer coating for the studied abrasives was determined by the formula:

$T_{a}=\frac{\left(a_{n}-a_{a}\right)}{2}, \mathrm{mkm}$

where $a_{n}$ - coated abrasive grain size;

$a_{a}$ - abrasive grain size uncoated.

Table 2. Results of measurements of abrasive grain

\begin{tabular}{|c|c|c|c|c|c|c|c|c|c|c|c|}
\hline \multirow{2}{*}{$\begin{array}{l}\text { № } \\
p / p\end{array}$} & \multirow[t]{2}{*}{ Test object } & \multicolumn{3}{|c|}{$a_{n, m m}$} & \multicolumn{3}{|c|}{$a_{a, m m}$} & \multicolumn{3}{|c|}{$T_{a, m k m}$} & \multirow{2}{*}{$\begin{array}{l}T_{c p,} \\
m k m\end{array}$} \\
\hline & & 1 & 2 & 3 & 1 & 2 & 3 & 1 & 2 & 3 & \\
\hline 1 & $\begin{array}{l}\text { Abrasive grain with polymer } \\
\text { coating No №1 }\end{array}$ & $\stackrel{m}{N}$ & ֻั & $\begin{array}{l}\circ \\
\stackrel{-}{m} \\
0\end{array}$ & 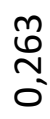 & 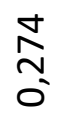 & 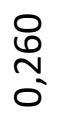 & ம & مْ & $\stackrel{\llcorner}{\sim}$ & 13,5 \\
\hline 2 & $\begin{array}{l}\text { Abrasive grain with polymer } \\
\text { coating No №2 }\end{array}$ & 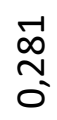 & $\begin{array}{l}\text { 广 } \\
\text { m } \\
0\end{array}$ & 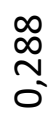 & 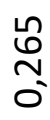 & $\begin{array}{l}\infty \\
\stackrel{\infty}{N} \\
0\end{array}$ & $\begin{array}{l}\stackrel{\sigma}{6} \\
\stackrel{N}{0}\end{array}$ & $\infty$ & $\sigma$ & ஸे & 8,8 \\
\hline 3 & $\begin{array}{l}\text { Abrasive grain with polymer } \\
\text { coating No №3 }\end{array}$ & 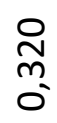 & ֻ & 엄 & 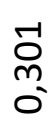 & $\stackrel{n}{N}$ & ঠั & ஸे & $\stackrel{n}{-}$ & $\infty$ & 9,6 \\
\hline
\end{tabular}


The final result is the arithmetic mean value of the coating thickness on the test sample of abrasive:

$$
T_{c p}=\frac{\sum T_{a}}{m}, \mathrm{mkm}
$$

where $m$ - number of measurements.

According to the measurement results, it was found that the thickness of the polymer coating does not exceed $50 \mathrm{mkm}$.

The sphericity of the abrasive polymer was estimated as the ratio of the horizontal projection area of the abrasive with a polymer shell to the area of the circle approximating the grain contour. To assess the spherical shape of the abrasive in the polymer sheath, a microscope with a magnification factor of 50 to 1500 was used with the ability to shoot with a digital camera, a computer and the KOMPAS-3D V17 software (Table 3).

The evaluation of the spherical shape of the abrasive grain in the polymer shell was carried out according to the formula:

$O_{u}=\left(1-S_{a} / S_{\kappa p}\right) 100 \%$,

where $S_{a}$ - area of the abrasive contour with a polymer sheath;

$S_{\kappa p}$ - area of a circle.

Table 3. Evaluation of the spherical shape of the abrasive in the polymer shell

\begin{tabular}{|c|c|c|c|c|}
\hline $\begin{array}{c}\text { № } \\
\text { abrasive }\end{array}$ & Picture & $\begin{array}{c}\text { Abrasive } \\
\text { area, } \mathrm{mm}^{2}\end{array}$ & $\begin{array}{c}\text { Circling } \\
\text { area, } \mathrm{mm}^{2}\end{array}$ & $\begin{array}{c}\text { Meaning } \\
O_{u}, \%\end{array}$ \\
\hline 1 & & 0,078761 & 0,089404 & $11 \%$ \\
\hline 2 & & 0,049881 & 0,058215 & $15 \%$ \\
\hline 3 & & & & \\
\hline
\end{tabular}

Based on the results of the assessment, it was found that the deviation from the spherical shape of the abrasive in the polymer shell does not exceed $15 \%$ [9].

\section{Conclusion}

Based on the data obtained for the manufacture of a prototype abrasive in a polymer sheath, the following conclusion was made:

1. The bulk density is determined by the original abrasive and does not depend on the processing modes. 
2. The spray pressure and the concentration of the polymer in the solution play an important role in the formation of the mass and size characteristics of the abrasive polymer. According to the results obtained, with an increase in the spraying pressure to $100 \mathrm{kPa}$, the uniformity of the coating increases to $100 \%$, and a coating thickness of about $30 \mu \mathrm{m}$ is formed.

3. The moisture content of the abrasive in the polymer shell is not affected by all factors, so the processing modes are selected taking into account the work on the critical values of the input factors.

4. The value of the concentration of the polymer in the solution does not significantly affect the quality of the surface. The greatest influence is observed on the value of the air flow rate. Its value should be chosen based on the maximum installation possibility. In our case, this is $40 \mathrm{~m} 2 / \mathrm{h}$.

5. The deviation of the specific gravity of the abrasive in the shell practically did not exceed $10 \%$. However, for some values with the maximum concentration of the polymer in the solution, the values of the increase in specific gravity up to $12 \%$ are recorded.

\section{Acknowledgement}

This research was supported by the Russian Science Foundation, grant no. 22-29-01599.

\section{References}

[1] Perec A (2018) Experimental research into alternative abrasive material for the abrasive water-jet cutting of titanium. Int J Adv Manuf Technol 97 (1): 1529-1540. https://doi.org/10.1007/s00170-018-1957-2

[2] Miao X, Qiang Z, Wu M, Song L, Ye F (2018) The optimal cutting times of multipass abrasive water jet cutting. Int J Adv Manuf Technol 97 (5): 1779-1786.

https://doi.org/10.1007/s00170-018-2011-0

[3] Barsukov GV, Zhuravleva TA, Kozhus OG (2017) Increasing of efficiency of environmentally friendly technology of AWJ of a glass fiber plastic. IOP Conf Ser Earth Environ Sci 50 (1): 012001. https://doi.org/10.1088/1755-1315/50/1/012001

[4] Sutowska M, Kapłonek W, Pimenov DY, Gupta MK, Mia M, Sharma S (2020) Influence of variable radius of cutting head trajectory on quality of cutting kerf in the abrasive water jet process for soda - lime glass. Materials 13 (19): 4277 14. https://doi.org/10.3390/ma13194277

[5] Momber A (2011) Hydrodemolition of concrete surfaces and reinforced concrete. Elsevier

[6] Perec A, Pude F, Grigoryev A, Kaufeld M, Wegener K (2019) A study of wear on focusing tubes exposed to corundum-based abrasives in the waterjet cutting process. Int J Adv Manuf Technol 104 (5): 2415-2427. https://doi.org/10.1007/s00170-019-03971-0

[7] Kozhus OG, Barsukov GV, Shorkin VS, Frolenkova L.Yu. Peculiarities of polymer deposition on the surface of abrasive grain to increase the efficiency of waterjet cutting // Fundamental and applied problems of technology and technology. 2021. No. 2 (346). S. 86-92. https://doi.org/10.33979/2073-7408-2021-346-2-86-92

[8] Kozhus OG, Barsukov GV, Shorkin VS, Stepanov Yu.S., Frolenkova L.Yu. Improving the efficiency of the installation for applying a polymer shell to an abrasive under critical technological conditions // Fundamental and applied problems of technology and technology. 2021. No. 3 (347). S. 91-99. https://doi.org/10.33979/2073-7408-2021-347-3-91-99

[9] Barsukov G.V., Kozhus O.G., Kozhus S.V., Pikalov D.N., Gukov A.A. Calculation of the fluidization rate of abrasive particles in the apparatus for applying a polymer coating // Certificate of registration of the computer program 2020617325, 03.07. Application No. 2020616334 dated 16.06.2020. 